\title{
SMART AgENT BASED SEARCH For AdMISSION IN INSTITUTIONS OF HIGHER LEARNING
}

\author{
Ricardo Adams $^{1}$ and Suresh Sankaranarayanan ${ }^{2,3}$ \\ ${ }^{1}$ Department of Computing, University of WestIndies, Kingston, Jamaica \\ adams.ricardo@gmail.com \\ ${ }^{2}$ Computing and Information Systems, Institut Teknologi Brunei, Brunei \\ ${ }^{3}$ Department of Computing, University of WestIndies, Kingston, Jamaica \\ pessuresh@hotmail.com
}

\begin{abstract}
Early admission systems saw people applying to universities by filling out applications forms and placing them in suitable envelopes and sending them through the local postal agency. This was not considered to be cost or time effective, and this method was also not efficient. This system however needed some improvement due to the huge workload on administrators. So researchers and software developers improved the system so that between 1999 and 2008 application and admission was done via the Internet. Also many Ranking system like ARWU, shanghai etc. been used for ranking the universities and colleges around the world which would enable people choosing the universities and colleges for education on factors like publication, funding, infrastructure and so.

The Internet has already brought the humans together in a new, exciting, and unexpected ways, and the same is also happening to our prevalent adoption of digital mobile devices that has paved the way for the development of many innovative applications in the commercial domain. While considering such mobile devices for an application towards higher education in an educational institution, there has been some amount of work done using intelligent agents. But still those agent based systems got some drawbacks which motivated towards developing the present Agent based system to provide Smart agent based system for higher Learning search not in Jamaican context alone but also elsewhere with these drawbacks alleviated. The agents developed will be based on using fuzzy preference rules and heuristics, to make accurate decisions based on the user's criteria or specifications using JADE-LEAP on Android handset. The system got Google map feature, intelligence in admission system and also warning for universities with low rating. These findings of this research will be presented as screenshots.
\end{abstract}

\section{KEYWORDS}

ARWU, JADE, LEAP, Android

\section{INTRODUCTION}

Early admission systems [1] saw people applying to universities by filling out applications forms and placing them in suitable envelopes and sending them through the local postal agency. This was not considered to be cost or time effective, and this method was also not efficient.

The 1994 era saw Norwegian Universities and Colleges being the early pioneers of Online Educational Admission Systems (OEAS). This system however needed some improvement due to the huge workload on administrators [2]. So researchers and software developers improved the system so that between 1999 and 2008 online application and admission was done via the Internet. The Internet has already brought the humans together in a new, exciting, and unexpected ways, and the same is also happening to our prevalent adoption of digital mobile devices that has paved the way for the development of many innovative applications in the commercial domain. The framework of M-commerce provides services like Mobile ticketing, Mobile banking, Mobile location based services, Mobile auctions, Mobile purchasing, etc. The 
possibilities and opportunities for usage are endless when considering mobile devices, as a universal device for mobile commerce applications. While considering such mobile devices for an application towards higher education in an educational institution, we generally come across selecting the best Universities with quality in overall teaching, available modern facilities and student resources, publicationslresearch interest, student feedback, funding for courses, clean environment and affordable rates. The tasks to be carried out towards getting these information can be humanly time consuming and sometimes also costly even with the using human agents. There of course exists lots of websites like webopedia, etc., which give the list of universities in the country. But everyone would want to know how good the university is and what is the review like by people. In addition there exists many ranking system like QS ranking, ARWU ranking and Times higher education [3] which ranks the universities in the country based on certain factors like academic peer review, faculty student ratio, international faculty, international students, citation per faculty and so on. But to get access to this information the user has to perform enormous Google search. In fact to our knowledge there is no such system that exists wherein ranking is based on feedback from the student community in addition to the one reported by the university and also accessible from a mobile device. So based on these there has been some research in terms of using Intelligent Agents in Mobile handset towards search of universities which uses fuzzy preferences to search for institutions and thereby showing rating of institutions based on feedback received from students compared to one received from those ranking sites based on information received from Institutions. But still these agent based systems got some drawbacks in terms of location of university using Google map, intelligent admission system by assessing the basic criteria and also sending warning to users and university authority towards lower ranking universities. These details are explained in forthcoming sections. Section 2 talk on Literature survey on Artificial Intelligence in Higher Education System. Section 3 talks on Smart Agent based System architecture developed towards Institutions of higher learning followed by algorithm. Section 4 talks on implementation using JADE-LEAP. Section 5 talks on Conclusion and Future work.

\section{ARTIFICIAl INTElligenCe In SEARCh AND AdMisSion}

This section here gives a detailed literature survey on Artificial Intelligence used in search systems followed by their usage in Educational Systems

\subsection{Artificial Intelligence in Search Systems}

Agent based technology has been integrated in AI systems to do web searches and make decisions for users. Agents are also utilized in expert systems and info bots. The concept of search agents has become important in both mainstream computer science and Artificial Intelligence (AI). Currently, search agents are being used in an increasingly wide variety of applications and they are the focus of intense relevance in many sub-fields of computer science and artificial intelligence [4]. Agent based systems and applications in the field of artificial intelligence, have given rise to new and improved software search agents which has evolved to meet the users specifications. An agent is always viewed as something that acts in an environment. Search systems incorporating agents with search algorithms have been used to solve various AI tasks. The key goal of intelligent search agents is to reduce user work and information burden. Intelligent search agents can provide services in online tutoring, searching and filtering of information or data, and so on.

Since the Internet has become one of the most useful and powerful source of information, Web Mining using web agents has become important which is the extraction of information automatically from web documents and services using data mining techniques. Inamdar et al 2009 paper suggests getting rich source of information, from hyperlinks among pages or Web usage information using web data mining technology based on intelligent search engine. Over the years AI has improved on various search algorithms such as best-first-search, depth-first- 
search, breath-first-search and heuristic search to name a few. Modern day search systems utilizes learning process components of AI search engines such as Google, Yahoo, Bing, and Ask.com to allow intelligent agents to communicate between users and network systems to gather and formalize knowledge. Artificial intelligence has a wide area of applications within search systems that are still under research. This research project will however focus on AI in Educational search and Admission Systems which are discussed in forthcoming sections

\subsection{Artificial Intelligence in Higher Education Admission System}

Gone were the days when applying to institutions required filling out blank forms and proof reading pages looking for errors. Afterwards packing the forms in 8 by 1 envelopes and sending them to Postal agencies [1]. We have entered a decade where admissions to higher learning can now be done online. Most Universities now allow prospective students to apply to their institutions via their websites. Some of these systems may differ from country to country and sometimes institution to institutions.

With the advent of Artificial intelligence, many admission systems have eliminated the traditional admission process. Institutions are now offering Web-based applications with AI technology integrated. This allows the student to apply without physically visiting the school to collect or submit applications [5].

In one of the research reported [6] there was the need to implement a system to facilitate the admission process. The system was web based and allowed the users to apply directly to the institutions. The system was called the Admissions Tutor. It was used to check all the required information for the student and it also ranked each students application. A student would be accepted or rejected based on the rankings of the institution and the grades of the potential student.

As the online Admission technology evolves, organizations like eadmissions.org allow parents to apply for placement of their children in nurseries and Kindergarten. This organization is comprised of the 33 London Authorities and Surrey County Council and they work together to make it easier for parents and care givers to apply for school places [7]

Admitting a student to a course is based on the individual university. They base their decisions on a number of factors, but primarily on the grades already achieved by the prospective students. As more applicants attain higher level of education, most institutions have devised a second means of admission criteria. This includes results from GCSE or standard exams, the schools they have attended and any personal information provided on the application. Most institutions have implemented similarity detection software to determine if the personal statements were written by a third party and hence are able to reject a student application [2]. In terms of this research, we will be rejecting the prospective student solely on not meeting the requirements for the programs they have applied for.

Beyond the use of AI in web enabled systems, there has been research [8] which showed an implementation of an Agent-based Student Mobility Support system in mobile devices. This involved the development of an agent system that offered support to individuals wanting to participate in student exchange programs. The system allowed the user to search for foreign institutions and programs based on user defined criteria such as room availability, course taught, required course credits and teacher appointments and availability. The work didn't have the ability to compare ratings of the institutions, support feedback mechanism nor any intelligence to assist students when choosing an institution to apply.

As Online admission application becomes more and more popular and in recent times they have also become more intelligent and allow for notifications.

Intelligent Agent Based University Search and Admission System [9] that was developed employs an intelligent agent, which replicates a human agent towards performing the similar 
search and admission activities that would incidentally improve the speed of the search and reduce cost considerably. The agents developed are based on using fuzzy preference rules and heuristics, to make accurate decisions based on the user's criteria or specifications. The agent here retrieves the list of universities based on user's specification and displays it on to Mobile handset of user along with feedback information of universities in terms of Quality of Education, Infrastructure, Environment, Cost etc. The feedback is based on what the students have reported about the university. The implementation was carried out using FIPA compliant JADE-LEAP agent development kit [10] on Android 2.2 handset.

Webtech a leading provider in online admission systems for Post Grad and Under Grad courses is one such evolved system. Users are notified via their mobile devices and PDAs. Developers of educational systems have now integrated artificial intelligence in their system which is cost efficient and has improve the user interaction experience when applying for institutions. This most times involves the use of Agents which will be discussed.

\subsection{Intelligent Agent}

The use of Agents is considered one of the most important aspects when improving on current methods for conceptualizing, designing and implementing software [10]. Agents are being used in applications ranging from large critical systems such as air traffic control to relatively small systems such as email filters [4]. The ability of an agent to traverse around a network, allows for agent to agent interaction and communication of information. Mobile agent technology has developed into a number of research areas. With the use of algorithms, agents are able to make decisions and return results for problem-solving tasks [11].

With the development of cutting edge toolkits and emulators, programmers can simulate mobile agent applications and hence enhance future agent technologies [12] . There are many agent Toolkits available like Aglets, Concordia, JAFMAS and so. But for our work which involves Mobile, the Java Agent Development framework (JADE) is one which is suited that is a fully compliant FIPA standards distributed middleware system with a flexible infrastructure allowing easy extensions with add-ons such as LEAP for mobile phones [10]. As such, the proposed system will use JADE along with add-on LEAP to create a multi-agent solution that will support Android 2.3 capable mobile devices

\subsection{Ranking of Higher Education System}

Rankings and ratings of colleges and universities are most times conducted by government, magazines, newspapers, and academics. An ordered combination of factors such as programs, departments, facilities etc. are used to assess a list of institutions in higher education [3]. The necessity for an international ranking of universities was highlighted in December 2003. Rankings of various types took into account aspects of excellence in research, student choices and final success with demographics. Surveys were also use to assist in ranking evaluations.

Rankings evaluations on institutions are sometimes done within a single country or institutions are assessed on a worldwide basis. The debate about ranking usefulness and accuracy is an on going one. The range in rating methodologies is ever expanding and the accompanying criticism of each indicates the lack of consensus in the field. There exists lot of websites like webopedia which gives the list of universities in the country. But everyone wants to know how good the university is and what is their review like by other people. Also there exists many ranking system like QS ranking, ARWU ranking and Times higher education which ranks the universities in the country based on certain factors like academic peer review, faculty student ratio, international faculty, international students, citation per faculty and so on. But to get access to this information the user has to perform Google search. But there is no such system exists where ranking is based on feedback from the student in addition to the one reported by the university and is accessible from mobile device. 
From the literature been surveyed it is cleared that there has been very little work reported on using Intelligent Agents towards higher education admission system. Also there are quite amount of ranking methodologies used towards ranking of universities worldwide. But none of them use feedback from students towards ranking but primarily depends on input from institutions only. So accordingly an Agent based system was developed on Android which enabled users to employ intelligent agents in searching for institutions using fuzzy preferences based on criteria and also retrieving institutions along with rating based on feedback from students. But still the agent based system got some drawbacks which was the main motivation for developing the smart agent based system which are explained in forthcoming section.

\section{Smart Agent Based Architecture For Higher LEARNing SEARCH AND ADMISSION}

It is important for us to explore and outline the process of what currently exists in the admission systems to a university, before we delve into details of our proposed system. The university educational institution admission system provides several sites and admission systems to students to enrol for admission to the university of their choice. Students may search through yellow pages directory or walk-in and fill out application forms. These systems work but however they generally require the applicant to do the bulk of the searches and application. Students often find this to be a time consuming and costly exercise, and also frustrating at times. Sometimes the universities are not of the quality and accreditation that the applicant expected. So seeing the inefficiencies in the current web based admission system, Intelligent Agent based Institutional Search and Admission system was developed in Android [9].

Intelligent Agent Based Institutional Search and Admission System [9] developed employs an intelligent agent, which replicates a human agent towards performing the institutional search and admission activities that would incidentally improve the speed of the search and reduce cost considerably. The agents developed are based on using fuzzy preference rules and heuristics, to make accurate decisions based on the user's criteria or specifications. The implementation was carried out using FIPA compliant JADE-LEAP agent development kit on Android 2.2 handset. But we noticed some drawbacks in the system that has been the motivation for this improved smart Agent based system.

The first drawback was that the system does not use GMAP facility of Android handset towards selecting the location for university search. Secondly the agent on retrieving the results to mobile handset only displays the list of universities and their rating but not the location of universities. Thirdly the system only displays the rating of the university based on feedback received from the students and not as how popular the university is in terms of a particular program or discipline based on enrolment/graduation, research papers published, etc. based on past search experience. Also the earlier agent based system was unable to determine if the User met the requirements for the program and hence it was unable to reject an admission made. The system only acknowledges for application made and do not possess intelligence towards admission system. Lastly the system possess not facility towards sending warning message to Institutions whose rating below certain value for improvement and also notify the user about those institutions during search process. These drawbacks were mitigated in the proposed Smart Agent based system in this research which is explained below with architecture, Data Flow Diagram, Sequence diagram and algorithm

\subsection{Smart Agent Based Architecture For Higher Learning Search And Admission}

Smart Agent based architecture as shown in Figure 1 shows how agents communicates and transfer information between themselves and how the agents interface with the user's Android phone. The smart agent models aspects of the admission process, by communicating and passing information between themselves and this is sent to the user's mobile device. The Android operating system supports multiple concurrent communications between the smart agents, 
allowing the agents to have the power of sending and receiving multiple messages at a time while still allowing full-duplex communication. The Android phone facilitates the use of three agents implemented on the mobile phone handset as shown in Figure 1, giving the user a more user friendly experience when using the application. The Android technology has created much popularity since its introduction by Android Inc. a firm which was bought by Google in 2005 . Users of the phone have the luxury and comfort of a PC running on their mobile device with a light weight platform that is flexible and facilitates data storage using SQLite. Android facilitates a core set of applications such as, SMS program, calendar, email client, maps, browser, built-in GPS, and much more added features. A customized virtual machine named Dalvik allowing easy running of libraries inside the mobile device. The Android platform is considered to be a good platform for users and developers, due to the opening of much of its OS system. Because of these reasons we decided to use the Android technology application.

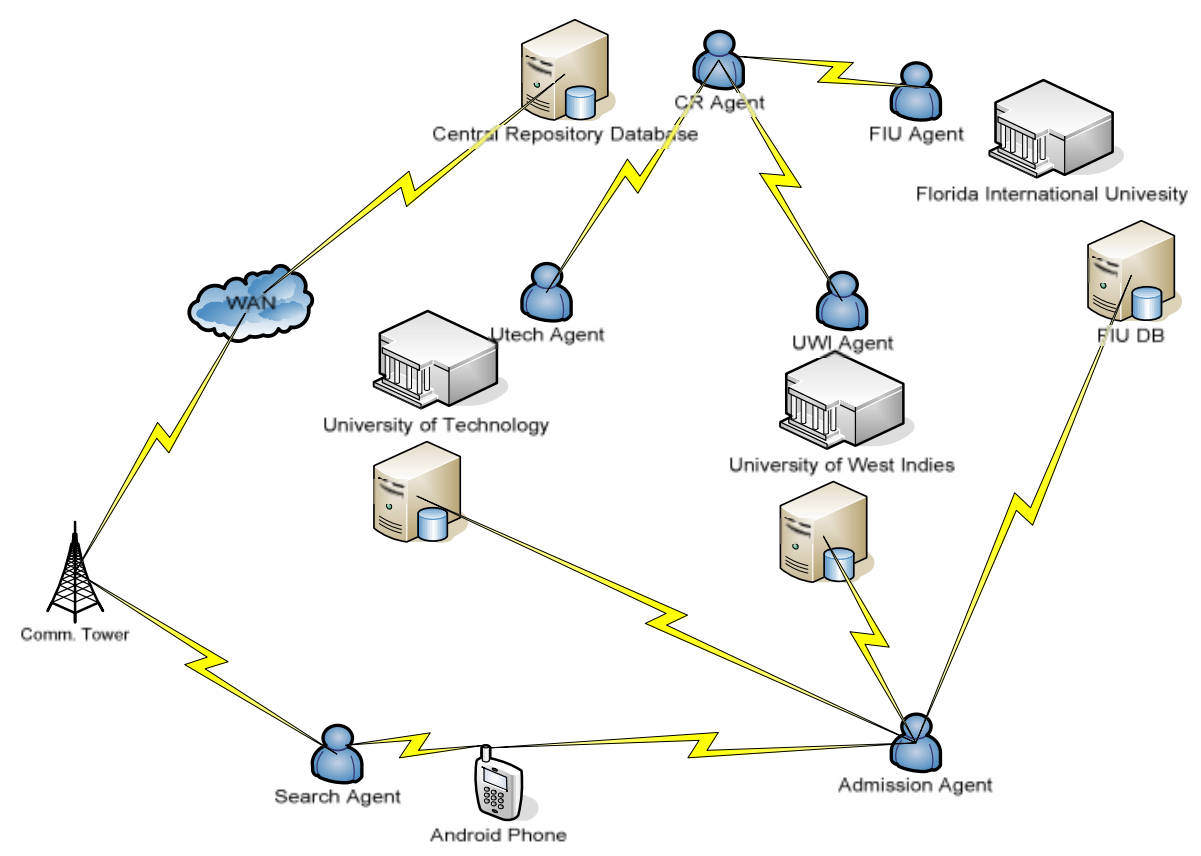

Figure 1 Smart Agent Architecture

The Smart Agent Based Search and Admission System utilizes several components within its architectural design. The main application platform requires an active mobile network inclusive of internet access. The Smart Agents interact and communicate with each other to return results based on the request of the user. The interaction from the user is to use the mobile graphical user interface (GUI) to initiate a university search and admission process. The request is communicated by the agents throughout the system to gather some results to the user who then makes the confirmation. We will now explore the roles of each component within the architecture.

- User - This is the user who wants to acquire information about a given university. The user is responsible for supplying the system the required search criteria that is used to generate the query for the requested data. The user will make an informed selection from the suggested results presented. 
- Mobile Device - The preferred choice of mobile phone for the smart Agent was the Android smart phone with the 2.3 platform version. The research was primarily done on an Android Emulator and there were limitations faced due to security restrictions on the newer platform. This affected some of commands issued within the application. The application was installed on the mobile phone. Within the application, the GUI displays the search and admission engine. Possible search criteria are collected from the system and displayed to the user. The mobile device also hosts three intelligent agents for the system; these are the search, admission and the feedback agents.

- Search Agent (SA) - The SA is hosted on the mobile device. The search agent is responsible for:

Collecting search criteria from the mobile device GUI.

$>$ Query the Central database Agent (CDBA).

$>$ Collect the generated results obtained from the CDBA.

$>$ Feed the results to the mobile device and display the result to the user

- Admission Agent (AA) - The AA is also hosted on the mobile device and has the responsibility of performing all admission related operations with the system. The AA negotiates within the system. Its major functions are as follows:

$>$ Collect the admission details from the mobile GUI.

$>$ Perform pre-checks relating to the university availability and user criteria. This would have been captured from the results from the Search Agent.

$>$ Perform checks on the applicant's qualification for a desired program

$>$ Keep track of the user's application to a program. This returns an application number to the user.

- Central Database Agent (CDBA) - The CDBA is considered the main system due to it doing majority of the work within the system. It is the link between the database and the results generated for the user to view. The CDBA has the responsibility to constantly perform multiple concurrent communications between the Smart Agents, allowing the agents to collect and forward information. The CDBA is responsible for:

$>$ Use query generated from the SA and match the criteria with the information stored in the database

$>$ Collect and store information about universities, with respect to fees, facilities, ratings, programs offered, location, contact details etc., from the respective university agents.

$>$ Collect and store the feedback results about universities from users and students in the central repository.

- University Agent (UA) - The UA resides inside each university. The UA communicates with the CDBA and updates and provides information to the universities. The UA interfaces with their respective university system components to gather information about fees, facilities, ratings, degrees offered, discipline, location and information updated or stored on the respective university's website. It is important to note that information stored by the CBDA from the UA is used to provide query matching based on some user's search criteria. The UA interfaces with the AA to provide universities with admission details, and this information is updated and stored in databases to be accessed by the university's administration. 
International Journal on Integrating Technology in Education (IJITE) Vol.2, No.2, June 2013

- Feedback Agent (FA)- The FA allows the users to rate a university based on fees, education and research facilities, infrastructure, security, general facilities, customer service and environment. The CDBA then stores these ratings for the FA to obtain and analyse the results of feedbacks over one, three and five year time periods. The overall ratings are fed back to the search agent to display to the user. The feedback agent is also responsible for notification to both the mobile users and the Universities. When a University is below the recommended ratings warning is sent in the form of an email.

\subsection{Smart Agent Algorithm}

Now based on Data Flow, Sequence diagram and Use Case diagram, we will now explore the algorithm of the system based on the architecture and design. Presented below is the Smart Agent algorithm:

- User enters search details of a university from his/her mobile device and submit request for a university. Search criteria includes: Discipline, Country, fees, percentage price mark up, suggested facilities they want, etc.

-When submission is made the search agent passes request to the Central Database Agent (CDBA) that will communicate with respective university agents to search and locate a list of adequate universities matching the search criteria of the user by applying the following intelligence:

$>$ If a university is available for a lower fee range with exact or nearest matching of facilities in the same or another location.

$>$ If a university is available for the price range specified with exact or closest matching of facilities in the same or different location or country.

$>$ If a university is not available within the specified price range, it finds a suitable university with the exact or nearest matching of facilities in the same or another location.

$>$ If no university is available within the user price range, agent finds a university with any price match with best matched facilities in same or different location.

-The university agents that satisfy the criteria will be displayed to the user's (GUI) mobile device for a possible selection showing location of university, nearby places, driving direction etc using Google Map.

-When a selection of a University is done, an Admission Agent (AA) is launched to facilitate admission. This form is to be filled out by the user. When the User decides to submit, the system will verify if the applicant has met the requirement for the selected program. If not satisfied, the application is rejected.

-The Admission Agent then submits the form to the selected University for admission, thus allowing the university's administrators to contact a prospective student.

-The system includes a feedback agent (FA) that allows the student to comment or give ratings on fees, programs, facilities and an overall rating of the university. Though this is present in the previous system (Suresh and Cox, 2012), Smart Agent allows notifications to be sent via emails and actions are taken when an institution falls below recommended ratings.

-The central database agent provides ratings on some aspect of the universities, which is the stored as averaged ratings calculated on all feedback received.

The implementation of Smart Agent based System been carried out using technologies like Java, JADE 4.0.1 with LEAP 4.0 and Android 1.0 add-ons, Android SDK and AVD Manager, Android 2.3 emulator, MySQL and eclipse (IDE). 


\section{IMPLEMENTATION USING JADE-LEAP IN ANDROID}

The implementation of the Intel-EISAS [9] was achieved using JADE 4.2 with LEAP and Android add-ons which is one of the latest Java Agent Development tool kit. When the application is launched for the first time, user is presented with the Login Screen as shown in Figure 2. If user doesn't have an account, they will need to register as shown in Figure 3. Once the user has logged in as shown in Figure 4, user is redirected to the Home Screen of the Application which allows performing the functionalities as shown in Figure 5.

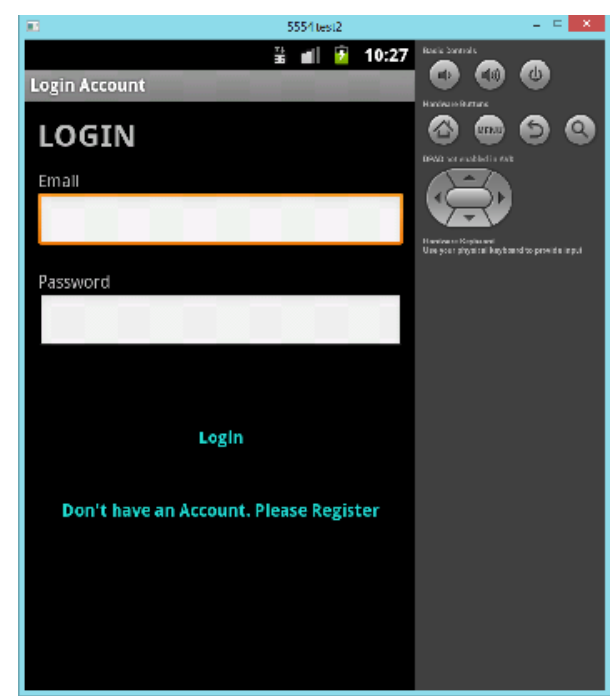

Figure 2 Login Screen

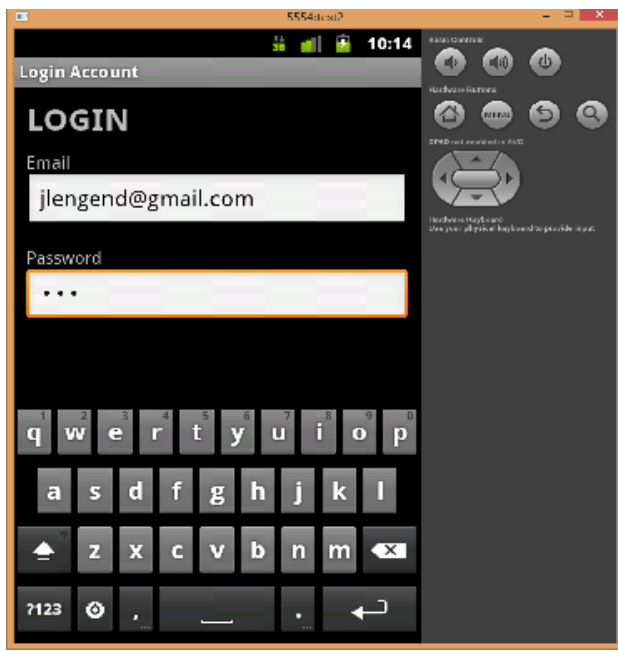

Figure 4 Login with Registered Credentials

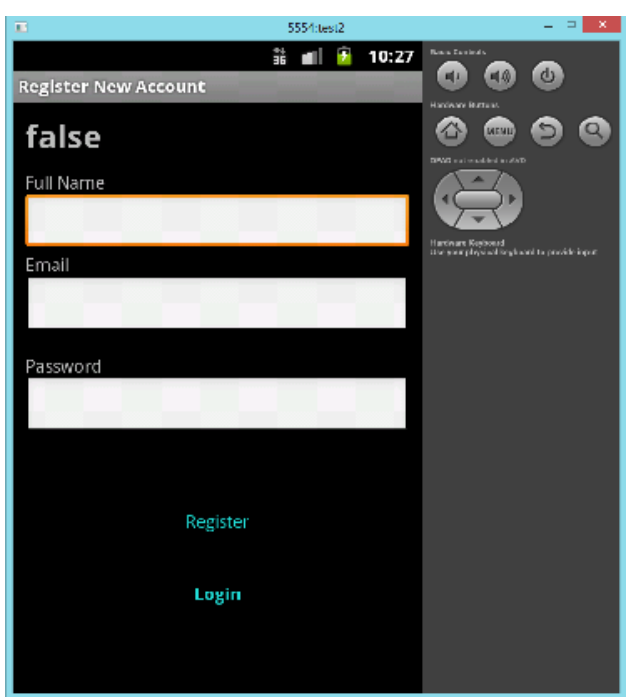

Figure 3 Register Screen

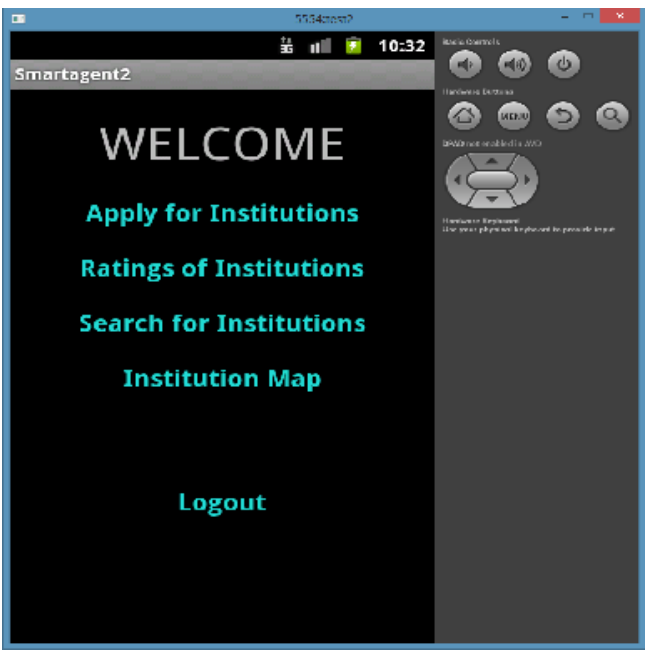

Figure 5 Home Screen for User

Once the user wants to search for an institution, user can initiate the Search Agent to find an institution. User would select criteria as given below that would influence their institution of choice which are:

-Discipline: This would include major fields of study such as Medicine, Information Technology and Business 
International Journal on Integrating Technology in Education (IJITE) Vol.2, No.2, June 2013

-Preferred mode of study. Whether the applicant is interested in Face to Face Program online and or a Part Time program

-Expected Cost. This is cost range for which the User can select how much money they are willing to pay to enroll in a program

-Country for the school. If the User is willing to travel or interested in a program offered in a country they would select from a drop down menu.

-Scholarship: Whether or not they want scholarship funding program.

- Distance: Proximity to University from place of residence

The User has the option of running the search on the provided selections or to continue the search with the inclusion of required facilities that the institution would have to provide. The facilities include a Library, Tutorials, Reading Room, Transportation Clubs and societies, Halls of Residence, Gym, Sports, Laboratory in the event the student wants to live on the campus. Based on criteria selected, search agent does the search of institution and associated programme. Once an institution is found, the user will get the option of applying or get rating information on the institution. In situations where an institution is not found based on the user's criteria, an advance search is done. These are explained below showing various agent intelligence scenarios.

Let us consider a scenario where the user chooses an Online IT Program located in Jamaica for a cost ranging $\$ 5000$ to $\$ 7999$ with no markup and other criteria like scholarship funded, distance to university and so forth as shown in Figure 6. The User has the option of running the search on the provided selections or to continue the search with the inclusion of required facilities that the institution would have to provide towards search like Library, Sports, Halls of residence as shown in Figure 7. Now based on the criteria and facilities included, search agent contacts the central database agents which are repository of all institutions with facilities. The agent possess the intelligence to search for institutions matching criteria with price of 5000-7999 in Jamaica and finds one institution which is University of Technology Jamaica with cost of 6500 along with rating for Programme and university as shown in Figure 8.

Let us consider another scenario where User searches for a Face to Face IT Program located in Jamaica for a cost ranging $\$ 8000$ to $\$ 10,999$ with university nearby and other facilities like Library, sports, Halls of Residence similar to one shown in Figure 6 and 7. Once user selected the criteria, the search agent is initiated which contacts the Central database agent towards searching for institutions with price range of 8000 to 10,999 in Jamaica for Face to Face IT program. But the search agent could not retrieve institutions matching the all the user's criteria in Jamaica instead the search agent applies the intelligence and retrieves the institutions to the users with best matching user's criteria with facilities in current and neighboring location as shown in Figure 9. The user can now make a decision whether to go with suggested institution or not. 


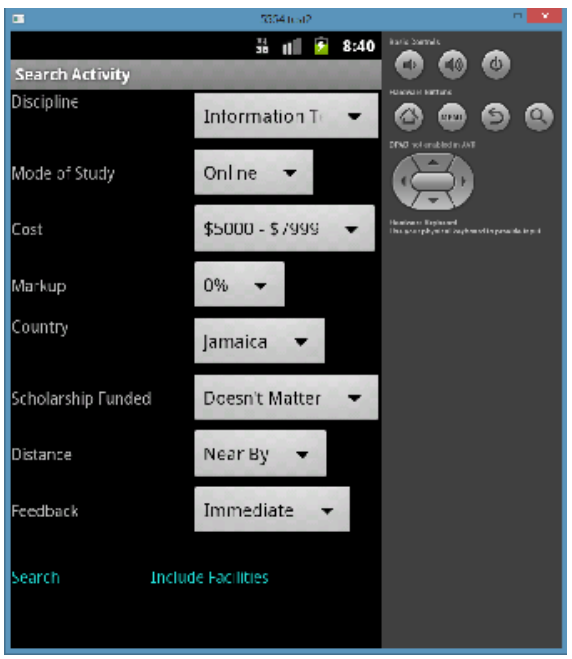

Figure 6 Search Agent user criteria

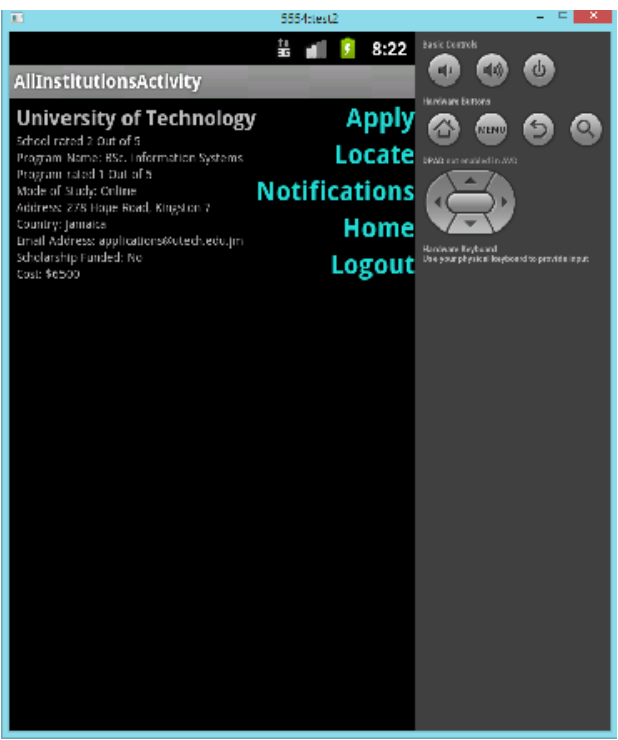

Figure 8 Search Result

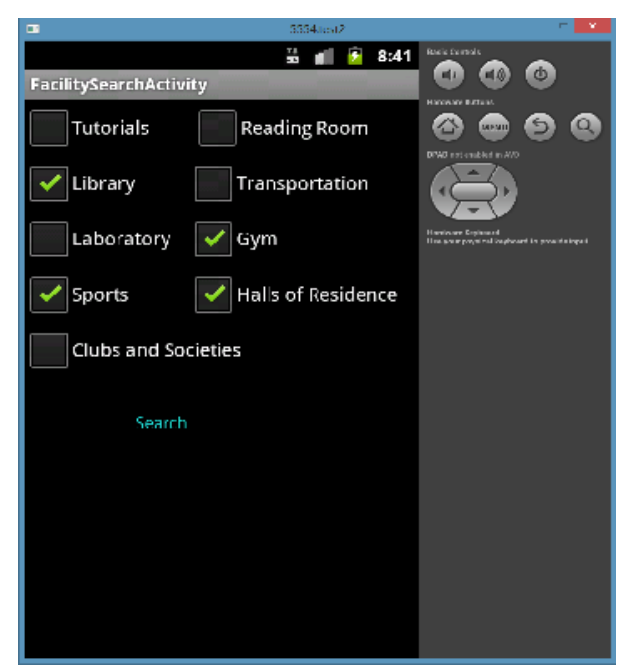

Figure 7 Facilities Inclusion

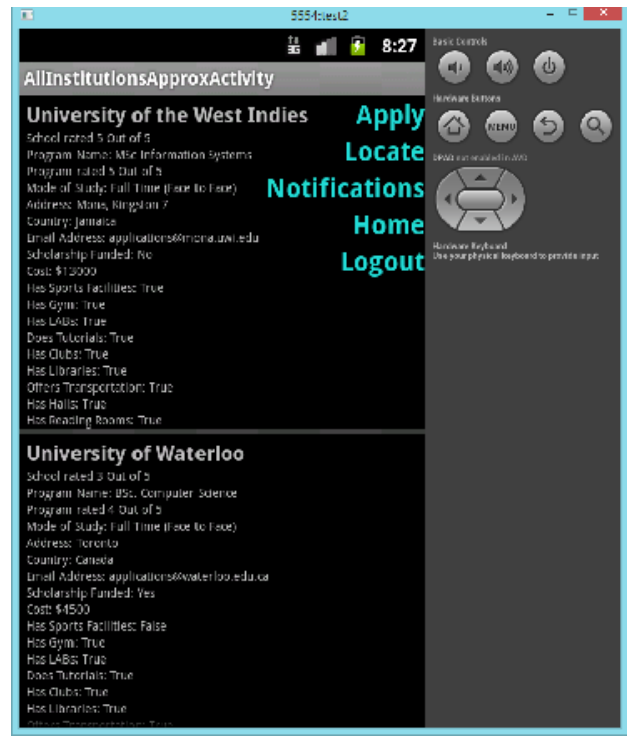

Figure 9 Best Match and Neighboring Institutions

Let us consider another scenario where User searches for a Online IT Program located in Jamaica for a cost ranging $\$ 8000$ to $\$ 10,999$ with university nearby and other facilities like Library, sports, Gym, Laboratory, Reading Room similar to one shown in Figure 6 and 7. Once user selected the criteria, the search agent is initiated which contacts the Central database agent towards searching for institutions with price range of 8000 to 10,999 in Jamaica for Face to Face IT program. But the search agent could not retrieve institutions matching the user's criteria instead the search agent applies the intelligence and retrieves the best approximated Program based on the cost chosen and facilities chosen. It also returns a suggested institution institutions to the users as shown in Figure 10. The user can now make a decision whether to go with suggested institution or not.

Let us consider another scenario where User searches for Face to Face IT Program offered in Canada for any cost with university nearby and other facilities like Library, Transportation, and Halls of residence similar to one shown in Figures 6 and 7. Once user selected the criteria, the 
search agent is initiated which contacts the Central database agent towards searching for institutions with any price in Canada for Face to Face IT program. The Search Agent returns Institutions offering a Full Time IT Program located in Canada at any given cost as shown in Figure 11.

Let us consider final scenario where User searches for Online IT Program offered in United States with cost ranging from $\$ 17000$ to $\$ 19999$ with university nearby and other facilities like Tutorials, Laboratory, Clubs and Societies, Gym similar to one shown in Figures 6 and 7. Once user selected the criteria, the search agent is initiated which contacts the Central database agent towards searching for institutions with price of 17000 to 19999 in United States for Online IT program. The search agent could not retrieve institutions matching the user's criteria instead the search agent applies the intelligence and retrieves the institutions the best approximated Program based on the cost chosen and facilities chosen in neighboring location. It also returns suggested institutions to the users as shown in Figure 12. The user can now make a decision whether to go with suggested institution or not.

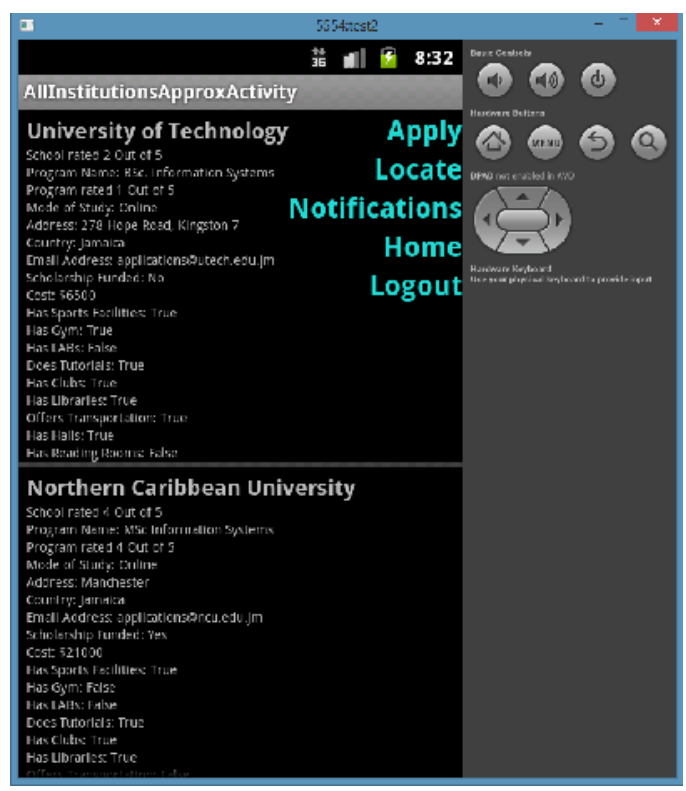

Figure 10 Best Match and Neighboring Institutions

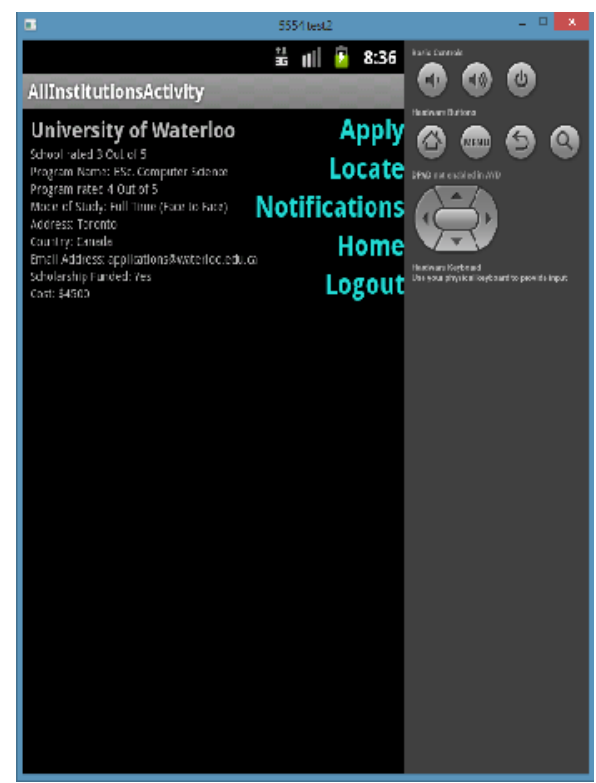

Figure 11 Search Results 
International Journal on Integrating Technology in Education (IJITE) Vol.2, No.2, June 2013

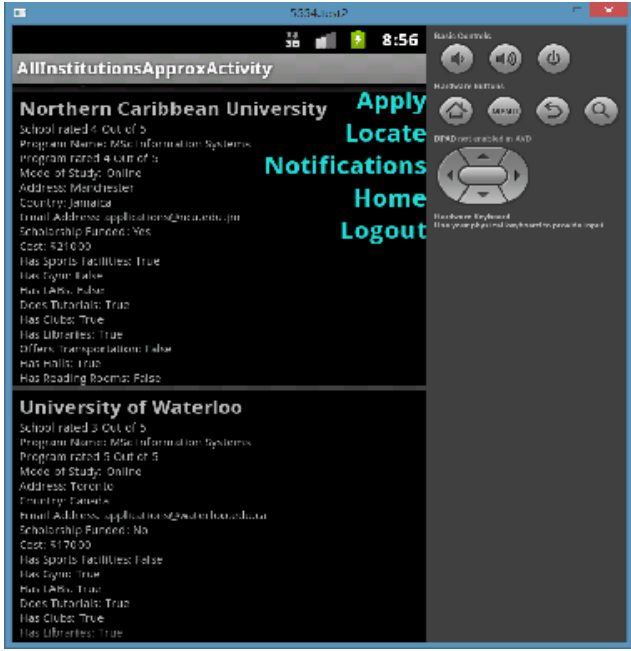

Figure12 Best Match with Neighboring Institutions

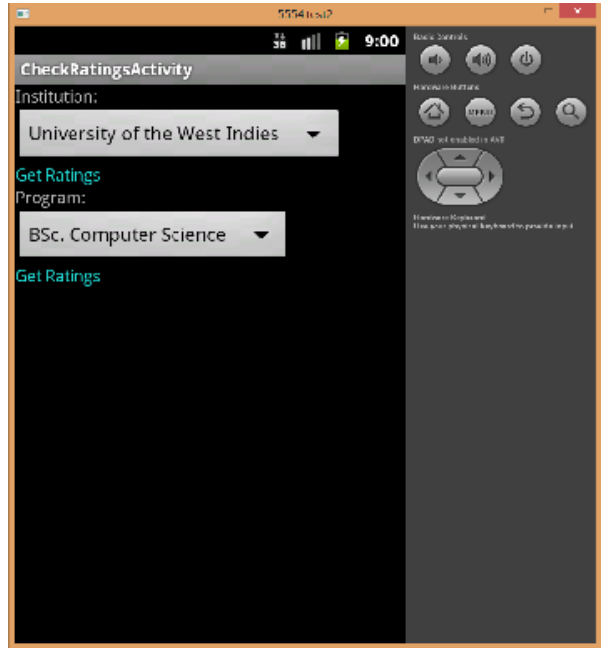

Figure 13 Check Ratings

Figure 13 shows the Universities and Programs for which the user can check the ratings. Once an Institution is chosen as shown in Figure 19 , the smart agent based system will automatically populate Programs for the chosen Institution as shown in Figure 14. The User can click "Get Ratings" under the Institution to view the ratings for the Institution and all available facilities as shown in Figure 15. In addition to viewing the rating of Institutions and selected facilities, the agent based system also allows user to select Programme offered in university which will display the ratings for the chosen program as shown in Figure 16 and 17.

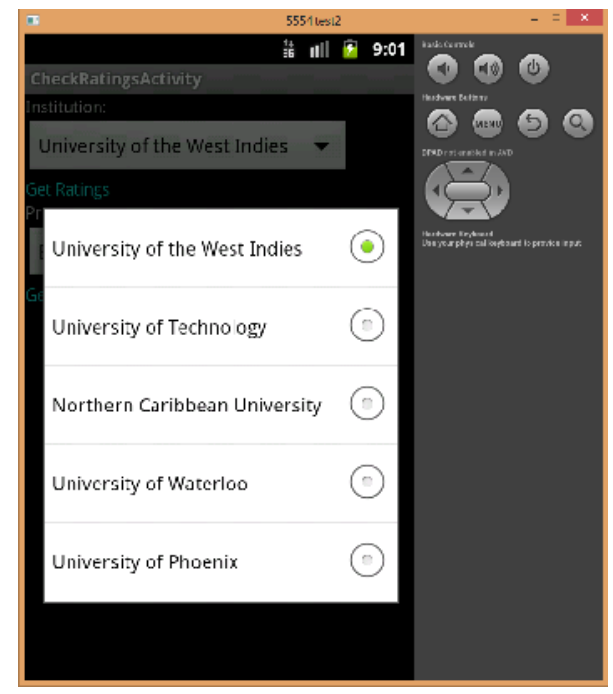

Figure 14 Institution Selection

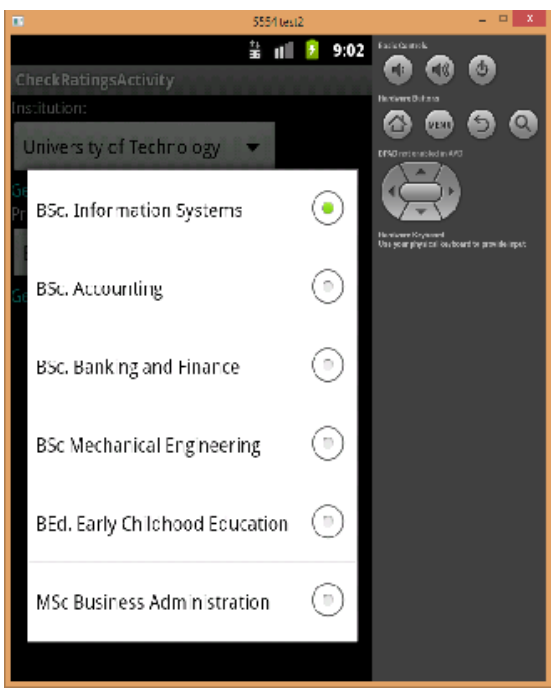

Figure 15 Program Selections 
International Journal on Integrating Technology in Education (IJITE) Vol.2, No.2, June 2013

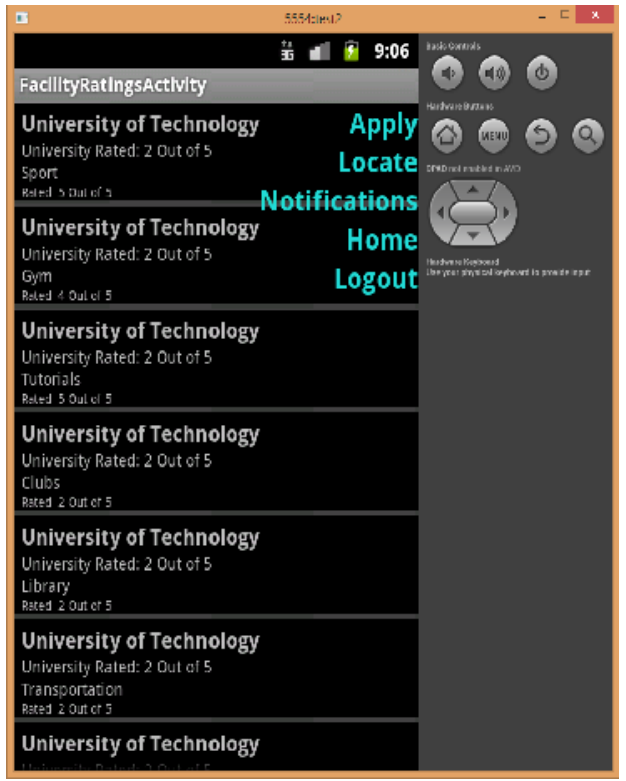

Figure 16 Ratings for Facilities - Institution

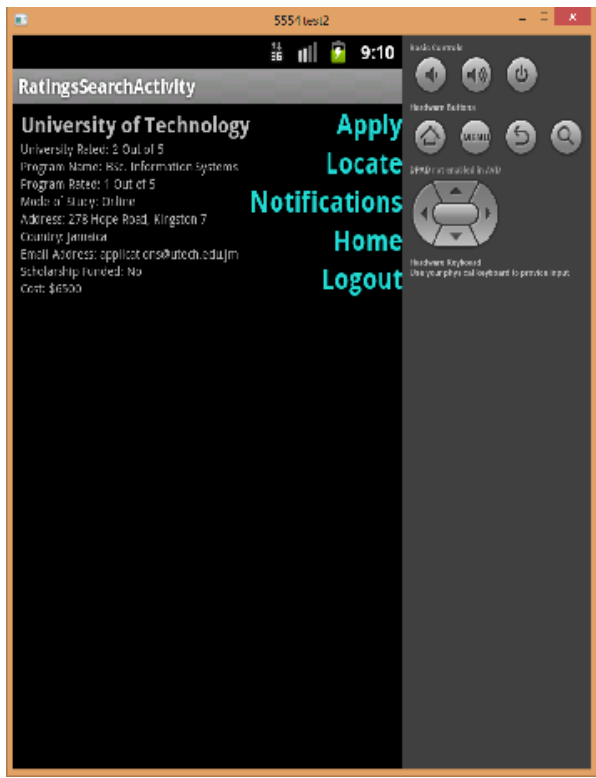

Figure 17 Rating for Programme

When user is satisfied with a program offered at an institution based on rating values, they can begin the application process. This involves checking if they meet the requirements for the program chosen by entering their qualifications by invoking Admission Agent as shown in Figure 18. User shows the list of institutions and Programme offered in the respective institution to be selected for applying. Each time a program is chosen, the prerequisites for the program is shown as seen in Figure 18. As seen for BA in History, the prerequisites are different than a BSc in Computer Science as shown in Figure 19.

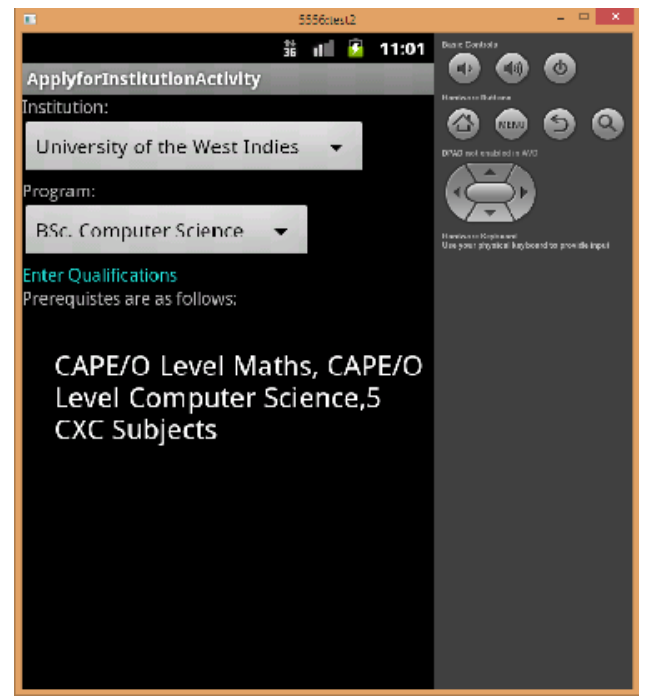

Figure 18 Admission Agent

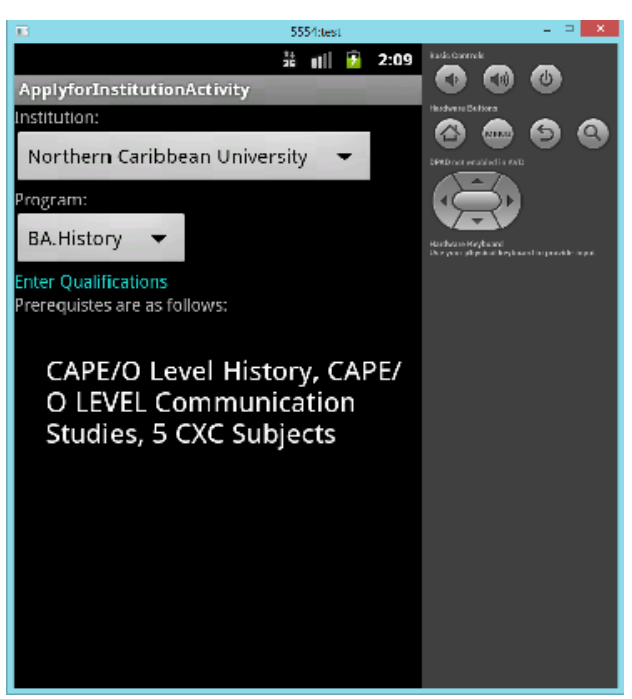

Figure 19 Programme Prerequisite

Once program is selected, the use selects "Enter Qualification". The User will enter Qualifications which consist of the institutions they went to and qualifications gained. The period of attendance and qualifications earned. For each program selected, there are prerequisites that the applicant has to meet. The user is given the opportunity to enter more than one qualification, 
thereby allowing them to further show their qualification for the course. If the similar qualifications are entered, the system will produce a notification. The Admission agent here possesses intelligence to check applications that they are met before admitting the person to the program. If not, they are automatically rejected. This is an improvement over previous system which only acknowledges once applied irrespective requirements met or not. These are shown in Figures 20 and 21. Also if the applicant enters the same subject twice, warning is issued by Admission agent. Figure 31 shows where the user enters CAPE qualification. Applicant will also meet the requirement since he has Math, Information Technology and 5 CXCs. Figure 22 shows where Admission Agent possess intelligence towards accepting Application based on requirements and accordingly application code is provided for future reference as shown in Figure 23.

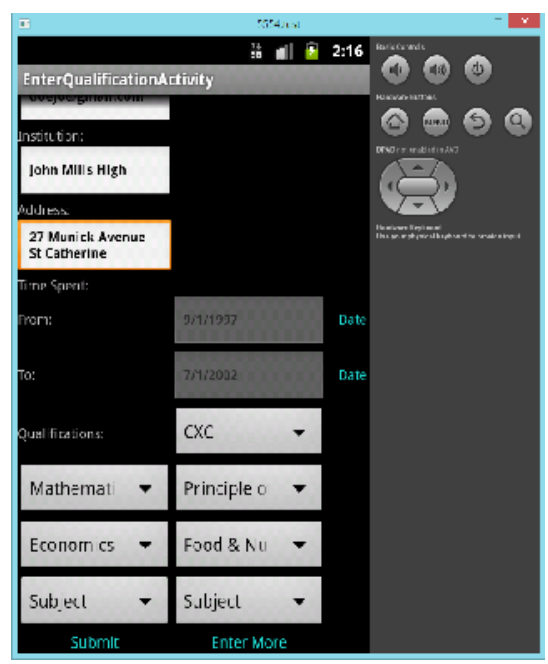

Figure 20 Qualification \& subjects

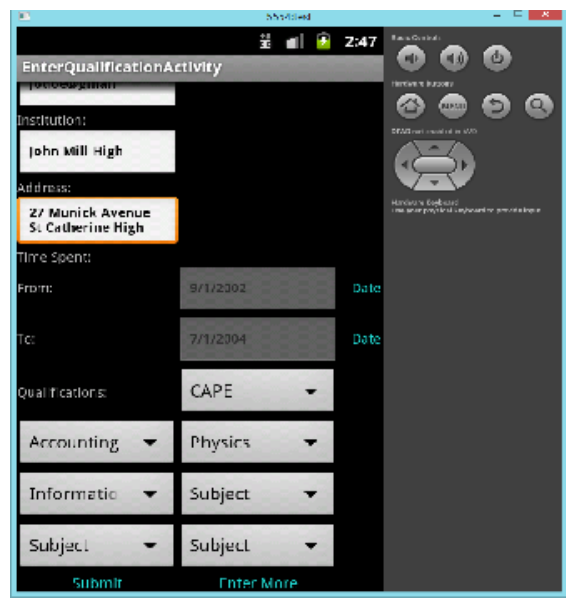

Figure 22 Satisfying Requirements

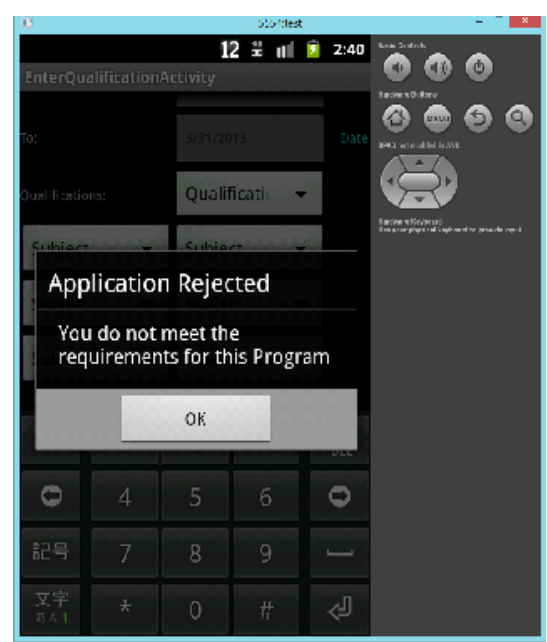

Figure 21 Application Rejected

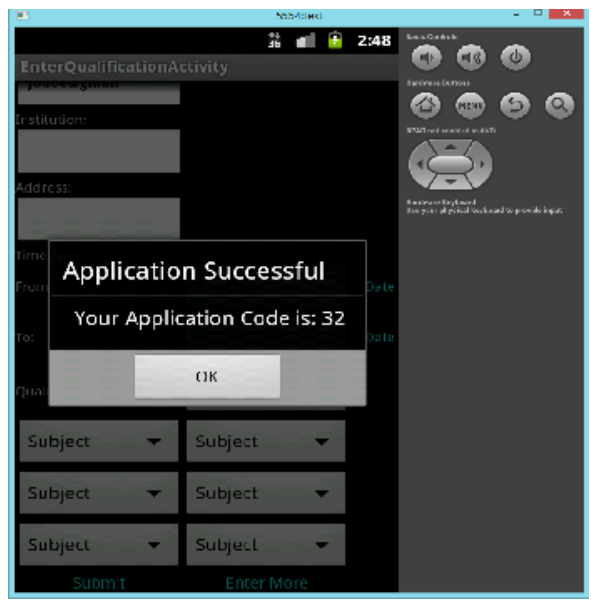

Figure 23 Successful Application

In addition to applying for institution of choice, the user can also get the location of the institution from the Google Map feature. In addition to getting location of Institution, user can also determine the best way to get the school and also view other locations near to the institution of choice. The User also has the ability to view all places nearby the institution. This could be added reason to attend the school. When an institution is selected, the user can also get direction whether by Walking, Driving or Commuting based on their location. These are shown in Figures 24 to 26 . 
International Journal on Integrating Technology in Education (IJITE) Vol.2, No.2, June 2013

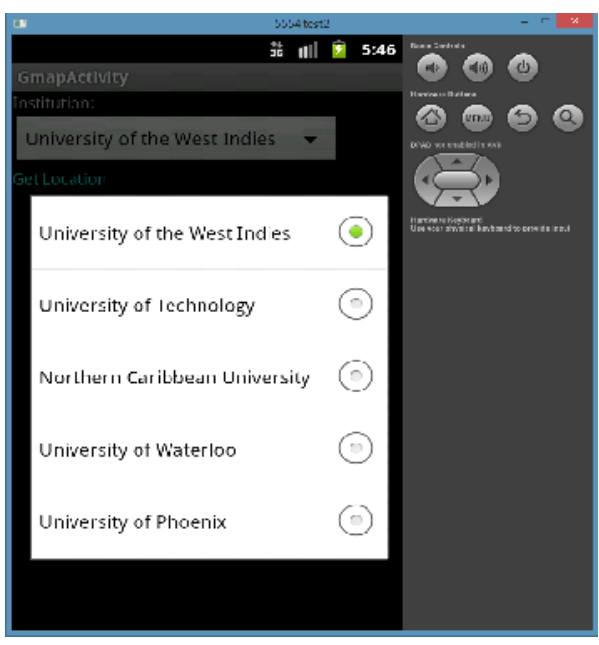

Figure 24 Institution Selection- Google Map

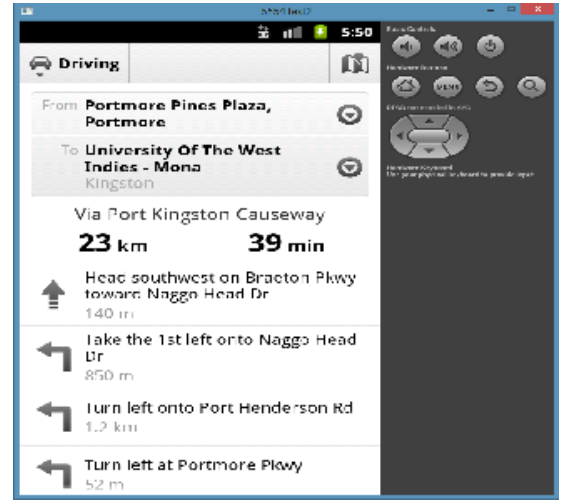

Figure 26 Driving Directions

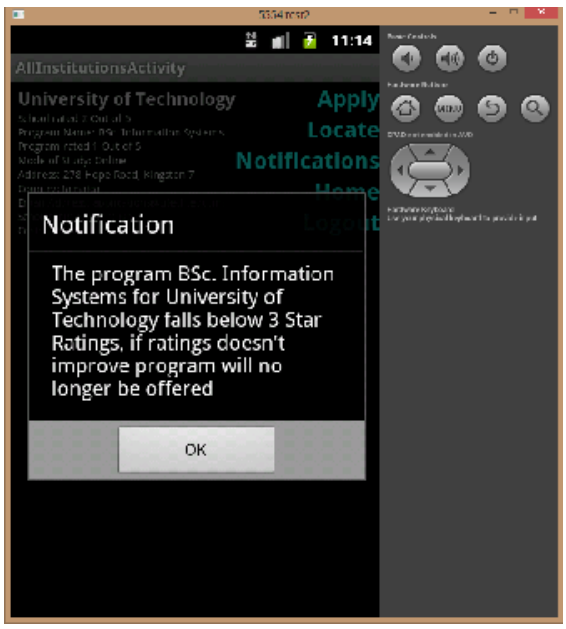

Figure 28 Notification on selected program

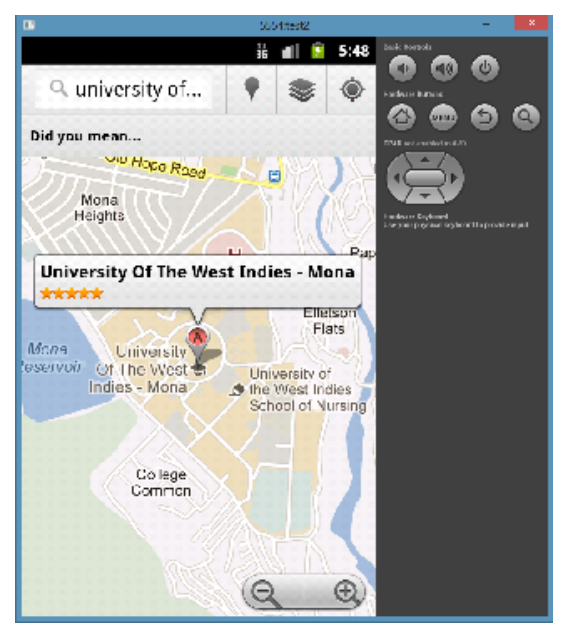

Figure 25 Location of Institution

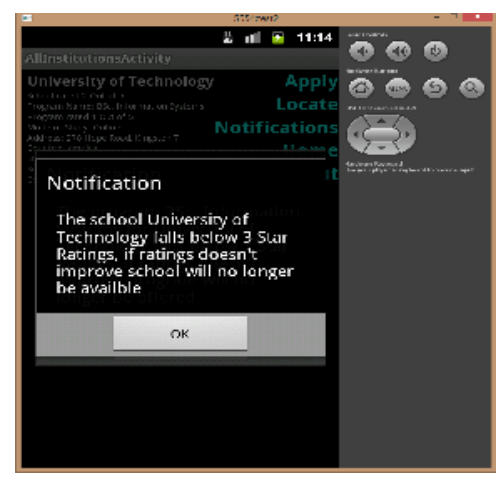

Figure 27 Notification on Institution

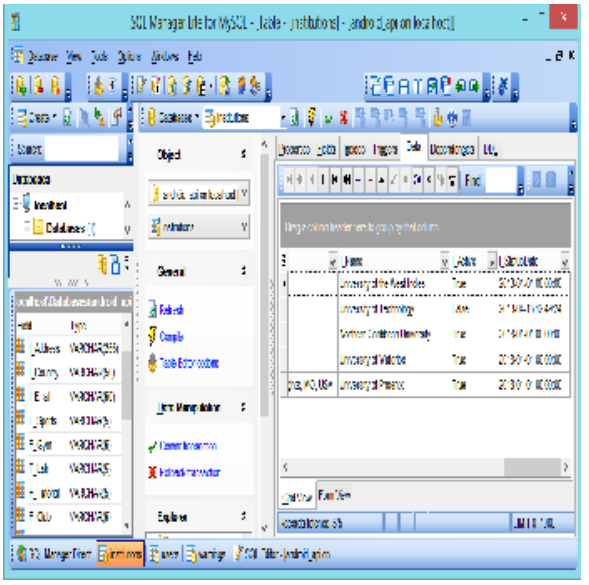

Figure 29 Institution is made inactive 
Based on the result Search agent, User is able to click on Notification for the university selected to see if there is any alert for them to view. The notifications that are generated will indicate if either the institution or program selected is rated below the minimum requirements. The alert would indicate the possibility of the institution no longer existing which are shown in Figures 27 and 28.

Under the admin profile, the user can send a warning letter to the institution when they fall below the minimum ratings of 2 . When a warning is to be produced, the smart agent calls the in-built Email App which allows for the emailing of the warning letter. The warning letter details are also saved to the database for future reference. If rating does not improve over time, Institution in this case is University of Technology is made inactive and will longer be available to future students. These are shown in Figure 29. Now say user logs into the system to check the rating of University of Technology which is no longer available as it is made inactive. Now after serious consideration and improvement by university, University council activates the university and is available. Once made active, user is now able to select university for applying and viewing the rating

\section{CONCLusion \& Future Work}

It is evident in today's world that there is a vast influx and birth of University institutions that has flooded the internet or the World Wide Web (WWW), and many of them lacks accreditation and credibility. But with mobile agent technology these vulnerabilities can be adversely and greatly reduced.

Mobile Search Agents can be used to verify and validate an accredited university within the applicant's geographical location. Once a university name is obtained, the agent automatically sources the information from accredited government and regulatory bodies' databases and websites in that countries locality to ascertain the validity and accreditation of the named university body. Ranking systems for world universities such as Shanghai Rankings, QS World University Rankings, Times Higher Education Reputation Rankings and Webometrics, are not ranking systems facilitating feedback ratings of students based on a university's education quality, research facilities, fees, environment, customer service and security. So accordingly Agent based system for Institutional search and Admission was developed (Suresh and Cox, 2012) i.e Intel-EISAS that mitigates above mentioned shortcomings. The system surrounds around Jamaican university and college institutions towards search based on user's criteria by applying fuzzy preferences. Though the above mentioned Agent based system saves time and efficient in selecting universities, but still it got some drawbacks which are mitigated in current smart agent based system developed in this research project. The results and tasks are generated by autonomous agents designed in a way that allow for cooperation, interoperability and communication within the system enabled the coordination of the entire search, selection and admission process thus allowing little or no human intervention resulting in a more time and cost effective process. In future the system developed can be integrated with agent learning capability which allows the agents to use past information to assist in searching for institutions rather than asking users to select all criteria. Also there is no payment feature as this requires Security improvement. This requires added WAP services in relation to credit card payments with the system.

\section{REFERENCES}

1. Guernsey, L., 1999. Spam Your Way to a Good Education; Online Application Forms Add to College Admissions Frenzy. Available at: http://www.nytimes.com/1999/12/23/technology/spamyour-way-good-education-online-application-forms-add-collegeadmissions.html?src=pmhttp://foba.lakeheadu.ca/serenko/Agent_Toolkits_Working_Paper.pdf; accessed April 30, 2013. 
International Journal on Integrating Technology in Education (IJITE) Vol.2, No.2, June 2013

2. Wikipedia 2010. Norwegian University and Colleges Admission service. Available at: http://en.wikipedia.org/wiki/Norwegian_Universities_and_Colleges_Admission_Service; accessed April 28, 2013.

3. College and university rankings (2010). Available at: http://en.wikipedia.org/wiki/College_and_university_rankings; accessed April 30, 2013.

4. Zambonelli, F., Jennings, N. Wooldrigde, M. 2003. Developing Multi-agent Systems: The Gaia Methodology. Transactions on Software Engineering and Methodology. Available at: http://www.csc.liv.ac.uk/ mjw/pubs/tosem2003.pdf; accessed April 30, 2013.

5. Naresh, S. n.d. Benefits of Online Schools Admission System. Available at: http://admission.ezinemark.com/benefits-of-online-schools-admission-system-31dfa34e691.html; accessed April 30, 2013.

6. Vignesh, B. 1993. Software Requirements Specification for Online University Admission System. VIT University 1993, IEEE Guide to Software Requirements Specifications (Std 8301993)

7. EAdmission n.d. An online Admission System for parents to find schools for their children. This can be found at: https://www.eadmissions.org.uk/eAdmissions/app?; accessed April 30, 2013.

8. Ganzha, M., Kuranowski, W., Paprzycki, M., Rahimi, S. and Szymczak, M. 2005. Designing an Agent-based Student Mobility Support System. Department of Computer Science, Gizycko Private Higher Educational Institute, Daszynskiego 9, 11-500.

9. Suresh, S. and Cox, L. 2012. Intelligent Agent based University Search and Admission System Android Environment. International Journal of Computer Information System and Industrial Management Applications, 4: 35-42.

10. Bellifemine, F., Caire, G., \& Greenwood, D. 2007. Developing Multi- Agent Systems with JADE. London: Wiley Publishing.

11. Reilly, D. 1998. Mobile Agents - Process migration and its implications. Available at: http://www.davidreilly.com/topics/software_agents/mobile_agents/; accessed April 23, 2013.

12. Yang, J., and Elhadi, S. 2010. Performance Evaluation of Agent Toolkits. Computer Science Department Acadia University Nova Scotia, Canada B4P2R6. Available at: http://www.springerlink.com/content/0a4nqqqbxfmblxx5/fulltext.pdf; accessed April 28, 2013.

Authors

Ricardo Adams holds Bachelor's degree in Computer Science and Electronics in 2008 and currently pursuing Master's degree in Computer Science from University of WestIndies, Jamaica since 2011. He is currently working as an IT Audit Consultant and also Part Time Lecturer in University of Technology Jamaica too. He is well versed in programming languages like Java, Php and so forth. His current research interests are mainly in Intelligent Agents, Mobile Computing.

Prof.(Dr) Suresh. Sankaranarayanan is currently an Associate Professor, Department of Computer \& Information Systems, Institute of Technology, Brunei (ITB - A technological university) and also Visiting Professor, Department of Computing, University of WestIndies, Kingston, Jamaica. He has supervised around 30 research students leading to M.Sc, ME, M.Phil and M.S degrees and currently supervising students leading to M.sc, M.phil and Ph.d respectively. He has got to his credit, as on date, about 50 fully refereed research papers published in the Proceedings of major IEEE international conferences, as Book Chapters and in International Journals. His current research interests are mainly towards 'Mobile and Ubiquitous Computing - Wireless Sensor Networks, Mobile Commerce, Intelligent Agents' used in the Health, Commercial and Engineering sectors. 